Hydrol. Earth Syst. Sci., 13, 1671-1683, 2009

www.hydrol-earth-syst-sci.net/13/1671/2009/

(C) Author(s) 2009. This work is distributed under

the Creative Commons Attribution 3.0 License.

\title{
Large zero-tension plate lysimeters for soil water and solute collection in undisturbed soils
}

\author{
A. Peters ${ }^{1, *}$ and W. Durner ${ }^{1}$ \\ ${ }^{1}$ Institut für Geoökologie, Technische Universität Braunschweig, Braunschweig, Germany \\ * now at: Institut für Ökologie, Technische Universität Berlin, Berlin, Germany
}

Received: 21 June 2009 - Published in Hydrol. Earth Syst. Sci. Discuss.: 30 June 2009

Revised: 2 September 2009 - Accepted: 3 September 2009 - Published: 18 September 2009

\begin{abstract}
Water collection from undisturbed unsaturated soils to estimate in situ water and solute fluxes in the field is a challenge, in particular if soils are heterogeneous. Large sampling devices are required if preferential flow paths are present. We present a modular plate system that allows installation of large zero-tension lysimeter plates under undisturbed soils in the field. To investigate the influence of the lysimeter on the water flow field in the soil, a numerical 2-D simulation study was conducted for homogeneous soils with uni- and bimodal pore-size distributions and stochastic Miller-Miller heterogeneity. The collection efficiency was found to be highly dependent on the hydraulic functions, infiltration rate, and lysimeter size, and was furthermore affected by the degree of heterogeneity. In homogeneous soils with high saturated conductivities the devices perform poorly and even large lysimeters (width $250 \mathrm{~cm}$ ) can be bypassed by the soil water. Heterogeneities of soil hydraulic properties result into a network of flow channels that enhance the sampling efficiency of the lysimeter plates. Solute breakthrough into zero-tension lysimeter occurs slightly retarded as compared to the free soil, but concentrations in the collected water are similar to the mean flux concentration in the undisturbed soil. To validate the results from the numerical study, a dual tracer study with seven lysimeters of $1.25 \times 1.25 \mathrm{~m}$ area was conducted in the field. Three lysimeters were installed underneath a $1.2 \mathrm{~m}$ filling of contaminated silty sand, the others deeper in the undisturbed soil. The lysimeters directly underneath the filled soil material collected water with a col-
\end{abstract}

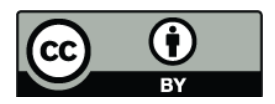

Correspondence to: A. Peters (andre.peters@tu-berlin.de) lection efficiency of $45 \%$. The deeper lysimeters did not collect any water. The arrival of the tracers showed that almost all collected water came from preferential flow paths.

\section{Introduction}

Pollutant movement toward the groundwater has become a severe problem in the last decades. To better understand the mechanisms of solute transport and to predict leachate masses and concentrations, appropriate in situ monitoring techniques for the vadose zone are required. Since every invasive soil water sampling system has an impact on the system behavior, it is still an unsolved problem to get representative measurements of pollutant fluxes through a certain horizontal area. This is even more problematic in heterogeneous soils with preferential flow paths, that are rather common on the field scale (Flury et al., 1994). Roth (1995) showed in a numerical investigation with Miller-similar media (Miller and Miller, 1956) that a network of flow channels occurs even in macroscopically homogeneous and isotropic soils if local heterogeneities of soil hydraulic properties are present.

Various strategies and geometries of sampling devices are used to collect leachate (Weihermüller et al., 2007). An inexpensive strategy to determine the chemical composition of the soil solution is soil coring. However, it does not allow flux estimation nor repeated sampling at the same site. Another strategy is to sample the soil solution by extracting it with a certain suction from the soil. This is done either actively by porous devices such as suction cups (Hagedorn et al., 1999) or suction plates (Kosugi and Katsuyama, 2004),

Published by Copernicus Publications on behalf of the European Geosciences Union. 
or passively by wick lysimeters (Boll et al., 1992; Jabro et al., 2008; Gee et al., 2009). The typically applied water sampling technique is the suction-cup lysimeter, which has been used since more than one century (Briggs and McCall, 1904). One of the disadvantages of suction-cup lysimeters is their limited size, which leads to the phenomenon that in heterogeneous or structured soils most of the suction cups are bypassed by preferential flow paths (Hagedorn et al., 1999). Similar are the problems for small wick lysimeters. Gee et al. (2009) simulated the performance of wick lysimeters with $20 \mathrm{~cm}$ diameter in homogeneous soils, and came to quite favorable results. Field installations of the lysimeters, however, showed a large variation in sampling efficiency. They attributed this to heterogeneity, preferential flow and wick lengths of the fluxmeters. The third strategy is to collect soil solutes passively by zero-tension devices, such as tile systems or zerotension monoliths or plate lysimeters. Although tile sampling integrates effects of spatial variability (Richard and Steenhuis, 1988), it may underestimate flow rates, because of soil water passing the tile system (Bergstrom, 1987). Monolith lysimeters allow the exact determination of water and solute fluxes (Meissner et al., 2008). However, lysimeter walls can create preferential flow paths (Cameron et al., 1979) and their high cost limits their use (Zhu et al., 2002).

Zero-tension plate lysimeters have no or small walls and collect soil water only if the soil water above the collecting pan has a positive pressure (Zhu et al., 2002). In all other cases water will diverge from the pan toward the dryer surrounding soil. This results in a low collection efficiency (Jemison and Fox, 1992). However, the collection efficiency of zero-tension plate lysimeters can be improved with larger sizes (Radulovich and Sollins, 1987; Robison et al., 2004). Russell and Ewel (1985) reported collection efficiencies of only $10 \%$ for zero tension lysimeters with an area of $162 \mathrm{~cm}^{2}$. Radulovich and Sollins (1987) found greater collection efficiencies with increasing plate sizes. They investigated the performance of lysimeter plates with areas of 162,500 and $2500 \mathrm{~cm}^{2}$ and found collection efficiencies of $10 \%, 13 \%$ and $26 \%$, respectively, in a coarse volcanic material with a bulk density of $<900 \mathrm{~m}^{-3}$. Jemison and Fox (1992) reported a highly variable collection efficiency of 13 to $92 \%$ and a mean of $52 \%$ for their lysimeters with a surface area of $4636 \mathrm{~cm}^{2}$ in a silt loam. Robison et al. (2004) installed a lysimeter with an area of $3.05 \times 2.13 \mathrm{~m}$ under an undisturbed coarse sand and reported a collection efficiency of essentially $100 \%$.

To insert plate lysimeters under undisturbed soils, they have to be installed horizontally from a pit. Usually, first a hole with the width and the depth of the plate has to be dug and then the lysimeter is installed (see Fig. 2 in Boll et al., 1997). These lysimeters are limited with respect to size due to instability of the overlying soil. For larger plates the soil may collapse before the lysimeter is inserted. Up to date it is therefore an unsolved problem to insert large lysimeter plates under undisturbed soils. One way to overcome this problem is shown by Robison et al. (2004). They installed their large plate horizontally with a bulldozer from a pit. However, this method is cost intensive, and due to the big forces used for installation it is questionable whether this method leaves the overlying soil undisturbed.

In this paper we introduce a new modular large zerotension plate lysimeter that can be installed manually under undisturbed soils. We investigate its performance with special focus on collection of preferentially flowing water. A numerical sensitivity study was carried out to investigate the collection efficiency of the lysimeters under different conditions. The aim of the numerical study was to find out how the collection efficiency is influenced (i) by the characteristics of the hydraulic functions in a homogeneous soil with unimodal pore-size distribution, (ii) by a structural secondary pore system, i.e., if the hydraulic functions are bimodal, (iii) by the infiltration intensity and the lysimeter size, and (iv) by local heterogeneities of hydraulic properties that lead to preferential flow paths. Furthermore, we compare the breakthrough of a solute that is collected by the plate lysimeter with the breakthrough in an undisturbed soil. Finally, the theoretical results are compared to those of a field investigation in a real soil.

\section{Materials and methods}

\subsection{Plate lysimeter design}

The key point in installing a large lysimeter plate in undisturbed soil is its modular system (Fig. 1). Single chamfers of a given length, made of stainless steel, are successively installed horizontally in the undisturbed soil from a pit, and connected to each other by rebated joints. The procedure of installation starts from an auger hole which is prepared to insert the first chamfer. Using this hole as access and transport space, sufficient soil at one side of the first chamfer is scratched out, until the next chamber can be pushed into its position. After the first chamfers are inserted, the space above them is stuffed with quartz gravel (diameter 0.5$0.8 \mathrm{~cm}$ ). This avoids a collapse of the overlying soil and also serves as a drainage layer. With this modular technique, which resembles a horizontal sheet pile wall, it is possible to install lysimeters of almost arbitrary width. In our field study, we installed lysimeter plates with an area of 1.25 by $1.25 \mathrm{~m}$. The plates had a decline of approximately $5 \%$ towards the pit. From there they drained into a stainless steel trench, also filled with the quartz gravel, which lead into a collection vessel (Fig. 2). The inner surface of the vessel was also stainless steel. A pipe (inner diameter $0.4 \mathrm{~cm}$ ) lead from the bottom of the vessel to the soil surface so that, after refilling of the access pit, water samples could be taken with a vacuum pump. Note, that for dry single grained sands a disturbance of the overlying soil might be unavoidable, so that 


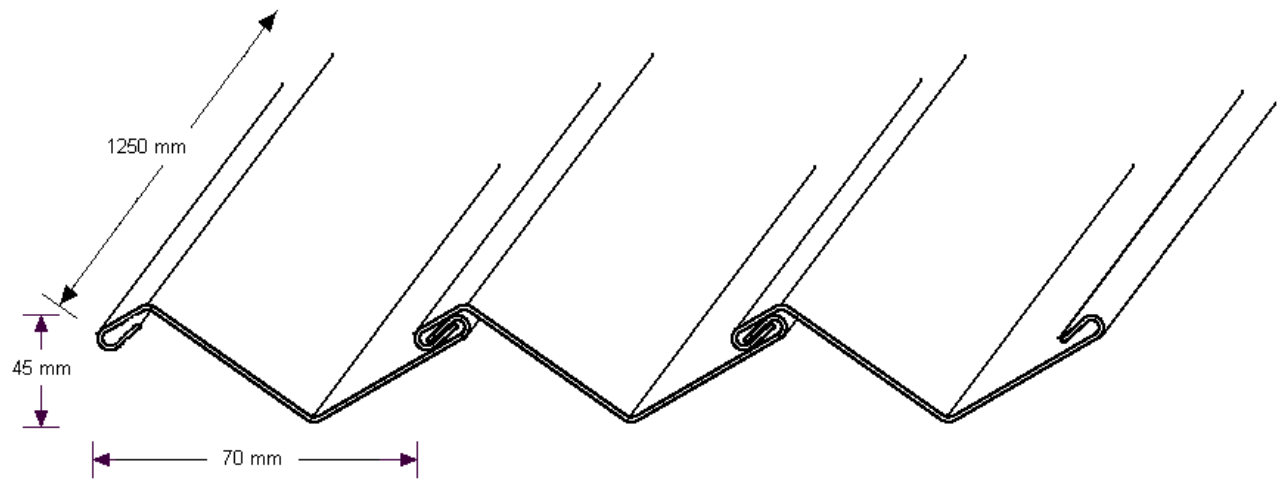

Fig. 1. Modular plate system. Single chamfers are $7 \mathrm{~cm}$ wide, $4.5 \mathrm{~cm}$ high, and $125 \mathrm{~cm}$ long. Chamfers are teethed together as in typical sheet pile walls.

this insertion technique has its limitations with respect to the soil material.

\subsection{Numerical sensitivity study}

The collection efficiency of plate lysimeters, defined as the ratio of the percolation rate through the lysimeter to the percolation rate in the undisturbed soil, is dependent on the lysimeter area (Radulovich and Sollins, 1987), the hydraulic properties of the soil, and the amount and temporal distribution of infiltrating water. In order to quantify the influence of these factors systematically, a numerical study with the finite element model HYDRUS-2D (Simunek et al., 1999) that solves the Richards equation for the two-dimensional case was conducted. We thus implicitly assume an infinite extension of the plates in the third dimension. The Richards equation for an isotropic medium is given by:

$C(h) \frac{\partial h}{\partial t}-\nabla[K(h) \nabla(h-z)]=r$,

where $C(h)=\partial \theta / \partial h$ is the soil water capacity function, $h[\mathrm{~cm}]$ is the pressure head, $t$ [d] the time, $z[\mathrm{~cm}]$ the depth coordinate, $\theta[-]$ the volumetric water content, $K(h)\left[\mathrm{cm} \mathrm{d}^{-1}\right]$ the soil hydraulic conductivity function, and $r\left[\mathrm{~d}^{-1}\right]$ a source or sink term.

The soil hydraulic properties were expressed by the uniand bimodal constrained van Genuchten expression for the retention function and Mualem's predictive model for the conductivity function. The retention function is given by:

$S_{\mathrm{e}}(h)=\sum_{i=1}^{k} w_{i} S_{\mathrm{e}_{i}}$,

where $S_{\mathrm{e}}=\left(\theta-\theta_{\mathrm{r}}\right) /\left(\theta_{\mathrm{s}}-\theta_{\mathrm{r}}\right)$ is the effective saturation, $S_{\mathrm{e}_{i}}$ are subfunctions of the system, $w_{i}$ are the weighting factors for the subfunctions, subject to $0<w_{i}<1$ and $\sum w_{i}=1$, and $\theta_{\mathrm{r}}[-]$ and $\theta_{\mathrm{S}}[-]$ are the residual and the saturated water contents. The effective saturations, $S_{\mathrm{e}_{i}}$, are expressed by:

$S_{\mathrm{e}_{i}}(h)=\left(1+\left(\alpha_{i}|h|\right)^{n_{i}}\right)^{1 / n_{i}-1}$,

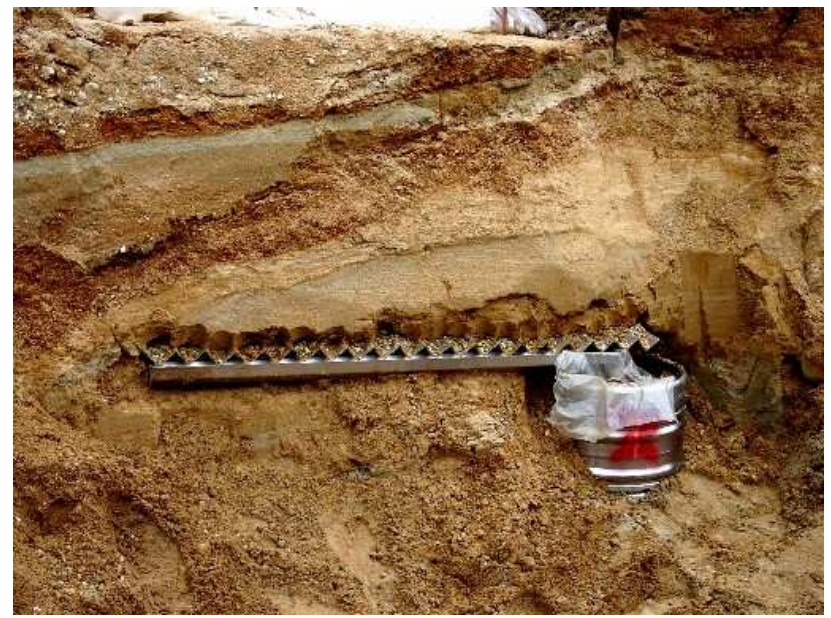

Fig. 2. Installed modular plate lysimeter prior to refilling of the access pit.

where $\alpha_{i}\left[\mathrm{~cm}^{-1}\right]$ and $n_{i}[-]$ are curve-shape parameters of pore-subsystems. For $k=1 \mathrm{Eq}$. (2) represents the retention curve of van Genuchten (1980), for $k=2$ the bimodal retention function by Durner (1994).

The relative unsaturated hydraulic conductivity function, $K_{\mathrm{r}}(h)$, as used in this study, is calculated from the soil water retention characteristic according to Mualem (1976)

$K_{\mathrm{r}}\left(S_{\mathrm{e}}(h)\right)=S_{\mathrm{e}}^{\tau}\left[\frac{\int_{0}^{S_{\mathrm{e}}} h^{-1} d S_{\mathrm{e}}(h)}{\int_{0}^{1} h^{-1} d S_{\mathrm{e}}(h)}\right]^{2}$

where $\tau[-]$ is a factor accounting for tortuosity and connectivity. To evaluate Eq. (4), the analytical solutions of van Genuchten (1980) for unimodal soils, and Priesack and Durner (2006) for bimodal soils were used. 

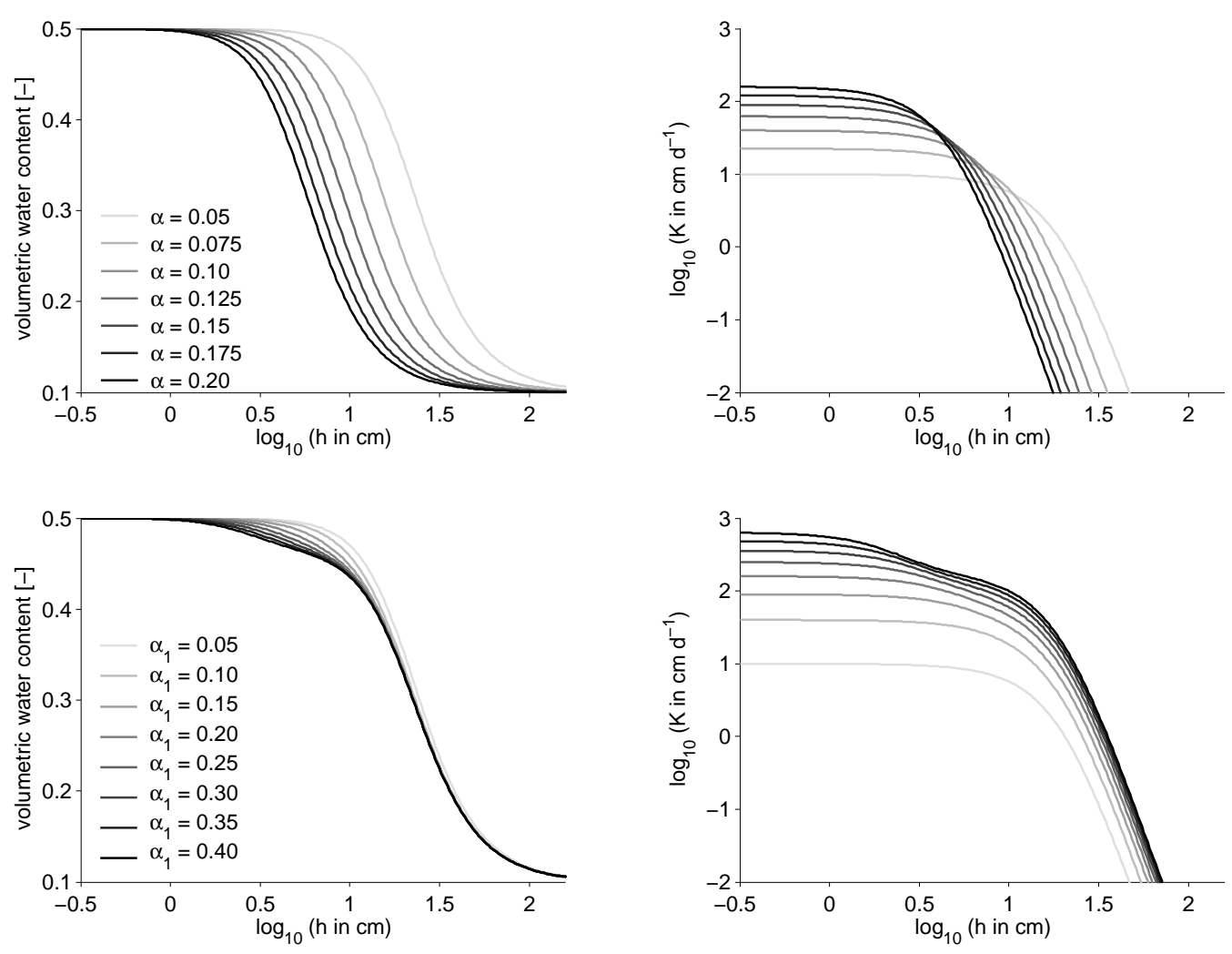

Fig. 3. Hydraulic functions that were used in the simulations. Upper row: unimodal functions. Lower row: bimodal functions.

In the numerical simulations a $300 \mathrm{~cm}$ wide and $200 \mathrm{~cm}$ high vertical soil domain was chosen. In the center of this domain a flat $(2 \mathrm{~cm})$ lysimeter plate with a width of $125 \mathrm{~cm}$ was inserted. Boundary conditions were a constant infiltration at the upper boundary of the domain, free drainage with unit gradient at the lower boundary, and zero fluxes at the sides of the domain. The lysimeter surface was set as a seepage face, i.e., zero flux as long as the local pressure head $h_{\text {seep }}<0$, and a Dirichlet condition with $h_{\text {seep }}=0$ if local saturation was reached. The seepage face boundary in the simulations represents the upper gravel surface of the installed lysimeters. The duration of all simulations was chosen such that steady-state conditions were reached. The mass balance error was less than $0.5 \%$ in all simulations.

\subsubsection{Collection efficiency in homogeneous soils}

The collection efficiency was investigated as a function of the hydraulic functions and infiltration intensity in homogeneous media with uni- and bimodal pore-size distributions. In the unimodal standard scenario, the hydraulic parameters were set to $\alpha=0.05 \mathrm{~cm}^{-1}, n=3.0, \theta_{\mathrm{r}}=0.1, \theta_{\mathrm{s}}=0.5$ and $K_{\mathrm{s}}=10 \mathrm{~cm} \mathrm{~d}^{-1}$. The tortuosity parameter was kept equal for all simulations at $\tau=0.5$. The parameter $\alpha$ was then varied from 0.05 to $0.2 \mathrm{~cm}^{-1}$, reflecting increasingly coarse soils.
The parameter $K_{\mathrm{S}}$ was related to $\alpha$ by the scaling theory of Miller and Miller (1956) (see Sect. 2.2.3), and increased from $10 \mathrm{~cm} \mathrm{~d}^{-1}$ for the reference case to $160 \mathrm{~cm} \mathrm{~d}^{-1}$ for the coarsest soil.

For the structured soil scenarios, a bimodal parametrization was chosen with a weight of $w_{2}=0.9$ for the textural part of the pore system and $w_{1}=0.1$ for the structural part. Saturated and residual water contents were as in the unimodal case. The textural parameters were $\alpha_{2}=0.05 \mathrm{~cm}^{-1}$, and $n_{2}=3.0$, as in the unimodal reference case. The structural parameter $n_{1}$ was also kept at $n_{1}=3.0$, but $\alpha_{1}$ was varied from 0.05 to $0.4 \mathrm{~cm}^{-1}$, with an associated increase of $K_{\mathrm{s}}$ from $10 \mathrm{~cm} \mathrm{~d}^{-1}$ to $640 \mathrm{~cm} \mathrm{~d}^{-1}$. This reflects increasingly large structural pores. Note that the bimodal reference simulation with $\alpha_{1}=0.05 \mathrm{~cm} \mathrm{~d}^{-1}$ is identical to the respective unimodal scenario. All parameter combinations and infiltration intensities of the numerical study are summarized in Table 1. The hydraulic functions of this study are plotted in Fig. 3.

The fluxes at the upper boundary were varied from 1 to $10 \mathrm{~cm} \mathrm{~d}^{-1}$. The infiltration intensity of the standard scenario was $4.0 \mathrm{~cm} \mathrm{~d}^{-1}$. 
Table 1. Parameter combinations for the numerical study. Scenarios: unimod hom=Unimodal functions with homogeneous distribution of hydraulic properties; bimod hom=bimodal functions with homogeneous distribution of hydraulic properties; unimod het=unimodal functions with heterogeneous distribution of hydraulic properties.

\begin{tabular}{lrrrrrrrrrr}
\hline scenario & $\begin{array}{r}\theta_{\mathrm{r}} \\
{[-]}\end{array}$ & $\begin{array}{r}\theta_{\mathrm{s}} \\
{[-]}\end{array}$ & $\begin{array}{r}\alpha / \alpha_{1} \\
{\left[\mathrm{~cm}^{-1}\right]}\end{array}$ & $\begin{array}{r}n / n_{1} \\
{[-]}\end{array}$ & $\begin{array}{r}w_{1} \\
{[-]}\end{array}$ & $\begin{array}{r}\alpha_{2} \\
{\left[\mathrm{~cm}^{-1}\right]}\end{array}$ & $\begin{array}{r}n_{2} \\
{[-]}\end{array}$ & $\begin{array}{r}K_{\mathrm{S}} \\
{\left[\mathrm{cm} \mathrm{d}^{-1}\right]}\end{array}$ & $\begin{array}{r}\tau \\
{[-]}\end{array}$ & $\begin{array}{r}\text { Inf. } \\
{[-]}\end{array}$ \\
\hline unimod hom & 0.05 & 0.5 & $0.05 \ldots 0.2$ & 3 & - & - & - & $10 \ldots 160$ & 0.5 & $1 \ldots 10$ \\
bimod hom & 0.05 & 0.5 & $0.05 \ldots 0.4$ & 3 & 0.1 & 0.05 & 3 & $10 \ldots 640$ & 0.5 & $1 \ldots 10$ \\
unimod het & 0.05 & 0.5 & 0.05 & 3 & - & - & - & 100 & 0.5 & 4 \\
\hline
\end{tabular}

\subsubsection{Lysimeter geometry}

The influence of the lysimeter size and rim width was investigated by applying the standard simulation scenario to lysimeters with four different widths $(50,75,125$ and $250 \mathrm{~cm})$. For the $250 \mathrm{~cm}$ wide lysimeter the width of the simulated flow domain was $600 \mathrm{~cm}$. The effect of lysimeter side walls was investigated with five different heights $(0,5,10,20$ and $40 \mathrm{~cm}$ ). The simulations were conducted for all bimodal soils and the standard infiltration rate of $4.0 \mathrm{~cm} \mathrm{~d}^{-1}$.

\subsubsection{Collection efficiency in heterogeneous soil}

The influence of heterogeneities of the soil hydraulic properties on the collection efficiency was investigated by assuming Miller-Miller similarity of the local hydraulic properties in a stochastic random field (Miller and Miller, 1956). In Miller-Miller similar media, the scaling relation between a point with the characteristic length, $\chi$, and the reference state $\left(\chi^{*}, h^{*}(\theta), K^{*}(\theta)\right)$ is given by $h(\theta)=h^{*}(\theta) / \chi$ and $K(\theta)=K^{*}(\theta) \cdot \chi^{2}$ (Sposito and Jury, 1990). The spatial distribution of $\chi$ was realized by using an exponential autocovariance model with equal correlation lengths in horizontal and vertical direction, $\Lambda_{x}=\Lambda_{z}=10 \mathrm{~cm}$. The scaling factor, $\chi$, was log-normal distributed with a mean of $\bar{\chi}=1$ and a standard deviation, $\sigma\left(\log _{10}(\chi)\right)$, of 0.5 and 0.75 , respectively. Combined with three different lysimeter widths (75, 125 and $250 \mathrm{~cm}$ ), this leads to six scenarios.

The infiltration intensity in all scenarios with heterogeneous soils was $4.0 \mathrm{~cm} \mathrm{~d}^{-1}$. The reference hydraulic functions were chosen as in the unimodal standard scenario, except setting $K_{\mathrm{s}}^{*}$ to $100 \mathrm{~cm} \mathrm{~d}^{-1}$. This value was chosen to ensure that a homogeneous soil with the reference soil hydraulic functions would have zero collection efficiency under these conditions. Figure 7 (top) shows a single realization of the two-dimensional distribution of $\log _{10}(\chi)$. In order to get representative simulation results, the simulations were repeated 400 times with randomly generated fields for each scenario.

\subsubsection{Lysimeter effect on solute flux}

Mass transfer into the plate lysimeter will deviate from the mass transfer that would occur in the respective depth without lysimeter, because the lysimeter alters the water flow field. To investigate this effect, we simulated the transport of a solute pulse, applied during stady-state water flow conditions with an infiltration intensity of $4.0 \mathrm{~cm} \mathrm{~d}^{-1}$, into a heterogeneous soil, with and without lysimeter. Initial solute concentration was zero for the whole domain. Solute transport was described by the convection-dispersion equation (CDE):

$\frac{\partial \theta c}{\partial t}-\nabla \cdot[\mathbf{D} \theta \nabla c]+\nabla \cdot[\boldsymbol{q} c]=r_{\mathrm{s}}$,

where $c\left[\mathrm{mmol} \mathrm{cm}^{-3}\right]$ is the volumetric solute concentration in the water phase, $\mathbf{D}\left[\mathrm{cm}^{2} \mathrm{~d}^{-1}\right]$ is the effective dispersion tensor, $\boldsymbol{q}=-K(h) \nabla(h-z)$ is the volumetric water flow vector and $r_{\mathrm{s}}\left[\mathrm{d}^{-1}\right]$ a source or sink term.

The longitudinal and transversal dispersivities $\left(\lambda_{z}\right.$ and $\left.\lambda_{x}\right)$ were set to 2.5 and $0.5 \mathrm{~cm}$, respectively, the diffusion part of the dispersion tensor was assumed to be negligible. The duration of the simulation was $20 \mathrm{~d}$. The simulations with and without lysimeter were carried out with identical heterogeneous distributions of soil hydraulic properties. The mass balance error for the solute transport in all simulations was less than $2 \%$.

The solute puls was applied by a Cauchy boundary condition at the upper boundary, with $c_{0}=100 \mathrm{mmol} \mathrm{cm}^{-3}$ for $0<t \leq 0.25 \mathrm{~d}$, and $c_{0}=0$ for $t>0.25 \mathrm{~d}$. At the sides of the simulated domain, no-flux boundaries were set, and solute transport into the lysimeter and across the lower free-drainage boundary was assumed to be purely convective.

To compare the mass flux into the lysimeter with the respective mass flux at the identical lysimeter-free situation, the flux concentration breakthrough, $c^{f}(t)$, at the horizontal lysimeter surface line was calculated by:

$c^{f}(t)=\frac{\int_{x_{1}}^{x_{\mathrm{r}}} c(x, t) q_{\mathrm{z}}(x) d x}{\int_{x_{1}}^{x_{\mathrm{r}}} q_{\mathrm{z}}(x) d x}$, 

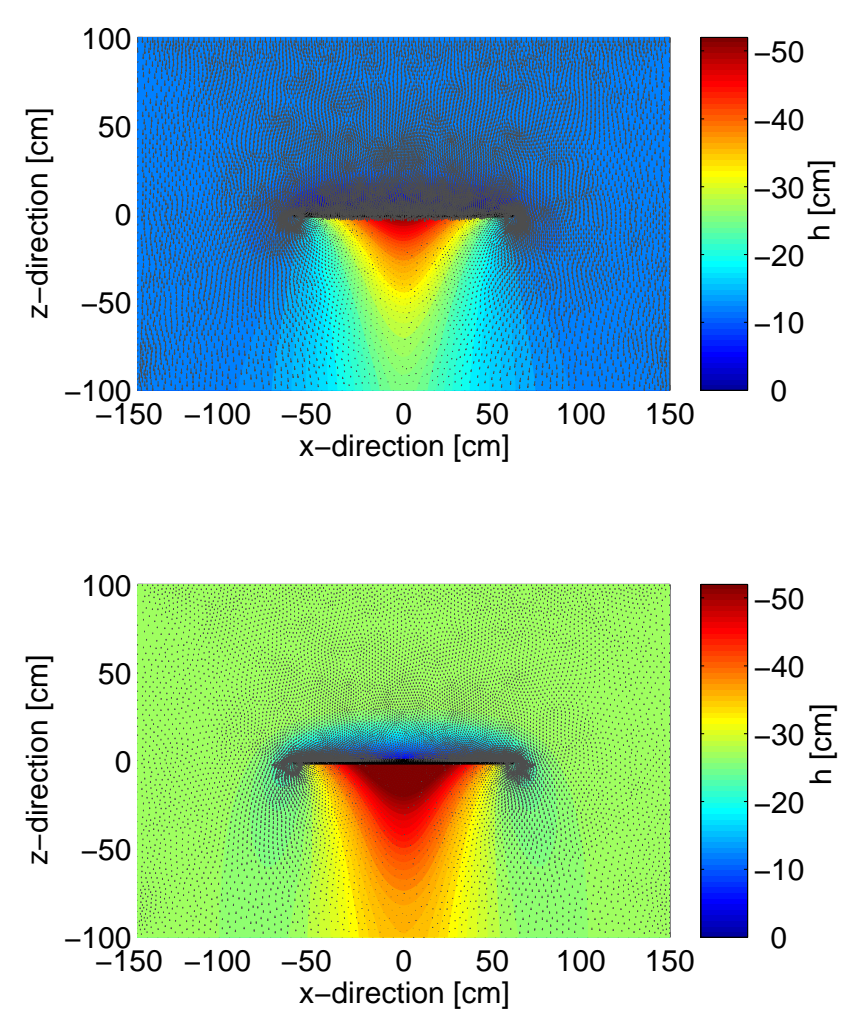

Fig. 4. Steady-state pressure head distribution in the 2-D-field. Arrows show flow direction and velocity (length). Top: unimodal hydraulic functions with $\alpha=0.05 \mathrm{~cm}^{-1}$; Bottom: bimodal hydraulic functions with $\alpha_{1}=0.4 \mathrm{~cm}^{-1}$ (complete bypass of the water). Infiltration intensity is $4.0 \mathrm{~cm} \mathrm{~d}^{-1}$.

where $x[\mathrm{~cm}]$ is the horizontal coordinate, $q_{\mathrm{z}}$ is the downward flux component, and $x_{1}$ and $x_{\mathrm{r}}$ are the left and right end positions of the line where lysimeter surface is located. $\mathrm{Nu}$ merically, the breakthrough was computed by integrating the local solute fluxes at 50 observation nodes on the grid points that were located equidistant on that line. The cumulative solute mass that passes the line until time $t$ is given by:

$M(t)=\int_{t_{0}}^{t} \int_{x_{1}}^{x_{\mathrm{r}}} c(x, t) q_{\mathrm{z}}(x) d x d t$,

where $t_{0}$ is the time at the beginning of the simulation.

\subsection{Field study}

In a field test, a total of seven lysimeter plates of $1.25 \times 1.25 \mathrm{~m}$ were installed in February 2003. Three lysimeter plates were inserted directly under a $1.2 \mathrm{~m}$ thick layer of dumped soil material. The upper $1.2 \mathrm{~m}$ of the original soil at the site had been removed before. The filling material was originally contaminated with polycyclic aromatic hydrocarbons and had been purified by a biological treatment prior to the deposition. Underneath, undisturbed glacial loams with variable textures ranging from loam to gravel were present. Four additional plate lysimeters were placed $50 \mathrm{~cm}$ to $100 \mathrm{~cm}$ below the base of the contaminated sand into the undisturbed soil. The soil surface was horizontal, and all seven lysimeters were located in sufficient horizontal distances to each other so that the distorted water flow field from one lysimeter could not influence the neighboring lysimeter.

After completion of long-time measurements under natural boundary conditions (data not shown), an irrigation experiment with application of two tracers was conducted from 11 to 15 October 2004. The goal of this experiment was to gain information about the transport behavior of the soil, especially with respect to the occurrence of preferential flow paths. $5 \mathrm{~mm}$ of a tracer solution with $8 \mathrm{~g} \mathrm{~L}^{-1}$ bromide as a nonreactive tracer and $0.35 \mathrm{~g} \mathrm{~L}^{-1}$ Brilliant Blue CFC (BB) as a reactive tracer were applied on the soil surface. After application of the tracers, the soil surface was irrigated with a total of $80 \mathrm{~mm}$ of water within five days. The irrigation rate was chosen to be below the maximum infiltration capacity of the soil, which was about $2.0 \mathrm{~cm} \mathrm{~d}^{-1}$. The homogeneity of the irrigation distribution was controlled with small plastic bottles (inner diameter $2.6 \mathrm{~cm}$ ) that were evenly placed on the soil surface. The irrigation was fairly homogeneous, with the coefficient of variation of $13 \%$. Water samples were taken 2 to 3 times a day until 15 October and then once at 28 October, 16 November and 14 December.

\section{Results}

\subsection{Sensitivity study}

\subsubsection{Homogeneous soils}

Figure 4 shows the steady-state pressure head distributions and water flow fields of two exemplary cases of the unimodal and bimodal scenarios. As expected, the plate lysimeter acts as a barrier for the water flow, so that the pressure head above the lysimeter increases, whereas it decreases underneath the lysimeters. In the unimodal standard scenario (Fig. 4, top) the pressure head above the lysimeter plate reaches zero and thus water is collected. The collection efficiency is $\approx 75 \%$. In the case with bimodal pore-size distribution and $\alpha_{1}=0.4$ (Fig. 4, bottom) the pressure head above the lysimeter does not reach zero, and thus the water is completely diverged from the lysimeter.

Figure 5 illustrates for all homogeneous soils the steadystate pressure head (left column) and hydraulic conductivity (right column) distributions directly above the lysimeter plate (standard lysimeter width $1.25 \mathrm{~m}$, standard infiltration rate $\left.4 \mathrm{~cm} \mathrm{~d}^{-1}\right)$. Coarse materials or materials with wide structural pores (high values of $\alpha$ or $\alpha_{1}$, and $K_{\mathrm{s}}$ ) are associated with smaller pressure head build-ups above the lysimeter and a decrease of the area with zero pressure head on the lysimeter surface. This is most pronounced for the bimodal soils 

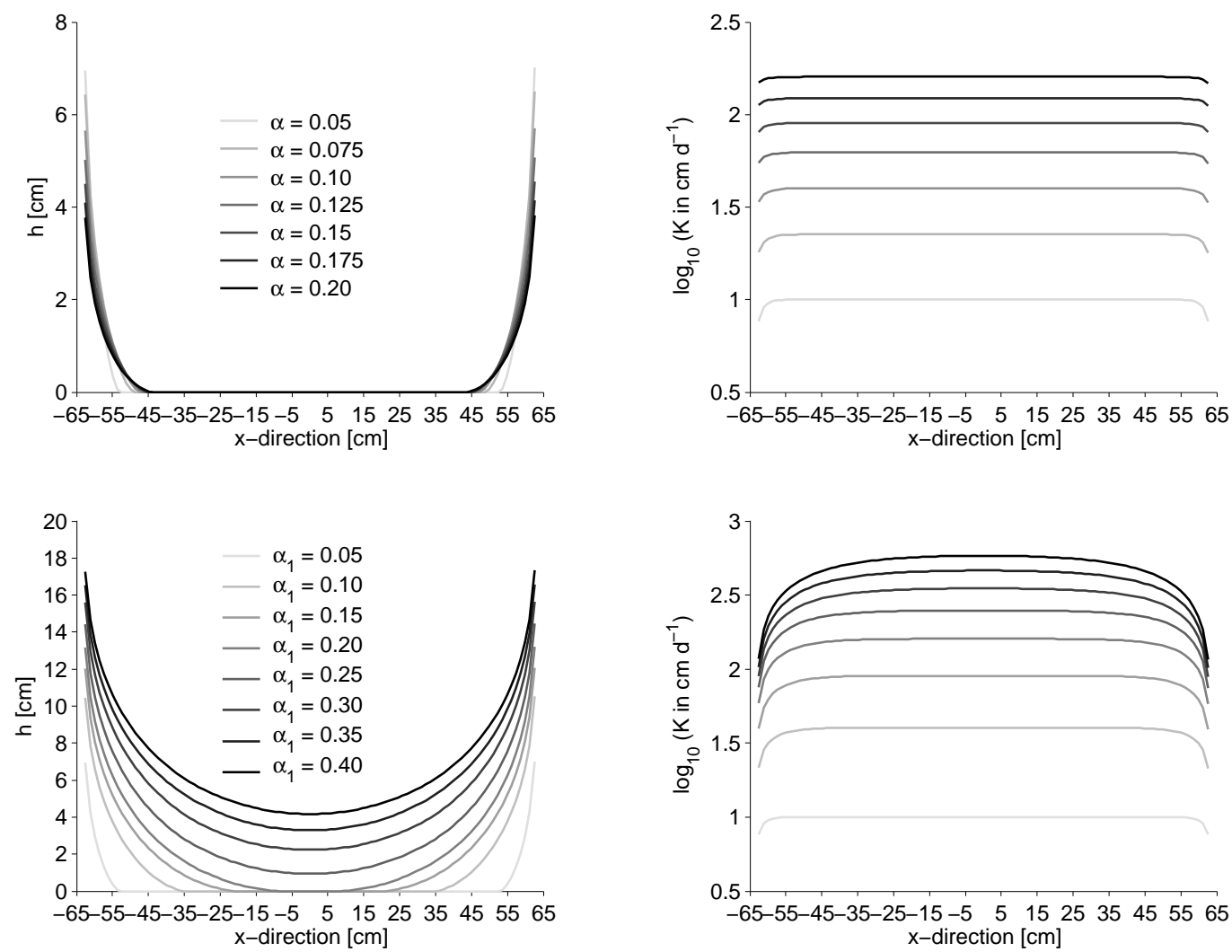

Fig. 5. Steady-state pressure head (left) and hydraulic conductivity distribution at lysimeter surface (right). Top: unimodal pore-size distributions; Bottom: bimodal pore-size distributions. Infiltration intensity $=4.0 \mathrm{~cm} \mathrm{~d}^{-1}$. The cases with $\alpha=0.05$, respectively $\alpha_{1}=0.4$ are the ones illustrated in Fig. 4.

where the pressure head on the lysimeter surface does not reach zero if $\alpha_{1} \geq 0.25$. Three effects control the extent of the saturated area. First, the hydraulic conductivities at and near saturation are higher for the coarser materials (Fig. 5, right column). Second, the pressure heads in the surrounding soil are lower for the coarser soils so that the lateral hydraulic gradient becomes greater. Third, the coarser materials have a rapid decrease of the hydraulic conductivity near saturation (Fig. 3), which restricts the size of the cross-section for active flow above the lysimeter. The third effect compensates effectively the first two ones and leads for the unimodal cases to almost equal pressure-head distributions for the different $\alpha$ values. The area with zero pressure head on the lysimeter surface varies only between 72 and $88 \%$.

Figure 6 summarizes the collection efficiencies of all simulation scenarios with homogeneous soils. The top row shows the collection efficiency as a function of hydraulic properties and infiltration intensity. High infiltration intensities lead to higher collection efficiencies. As already explained above, different values for $\alpha$ and $K_{\mathrm{S}}$ compensate each other in soils with unimodal pore-size distributions, so that the collection efficiency is more or less equal for a certain infiltration intensity (Fig. 6, top, left). None of the cases reaches a collection efficiency of one. For the structured soils with bimodal pore-size distributions, higher values of $\alpha_{1}$ and $K_{\mathrm{s}}$ lead to lower collection efficiencies, which easily become zero (Fig. 6, top, right).

\subsubsection{Lysimeter geometry}

Figure 6 (bottom, left) shows the collection efficiencies as a function of the lysimeter size for all bimodal soils and the standard infiltration rate of $4 \mathrm{~cm} \mathrm{~d}^{-1}$. The small lysimeter with a width of $50 \mathrm{~cm}$ collects water only if $\alpha_{1} \leq 0.05$. As expected, larger lysimeter sizes yield higher collection efficiencies. But even very large lysimeters with a width of $250 \mathrm{~cm}$ have a collection efficiency $\leq 40 \%$ if the soil material has a sufficiently high near-saturated conductivity. In contrast, rims of different height to control the divergence of the flow field (Gee et al., 2002) have a dramatic influence on the collection efficiency. This is illustrated in Fig. 6 (bottom, right). Already relatively small lysimeter rims improve the collection efficiency significantly. A rim height of $40 \mathrm{~cm}$ leads to a collection efficiency of 1 in all simulated cases. 

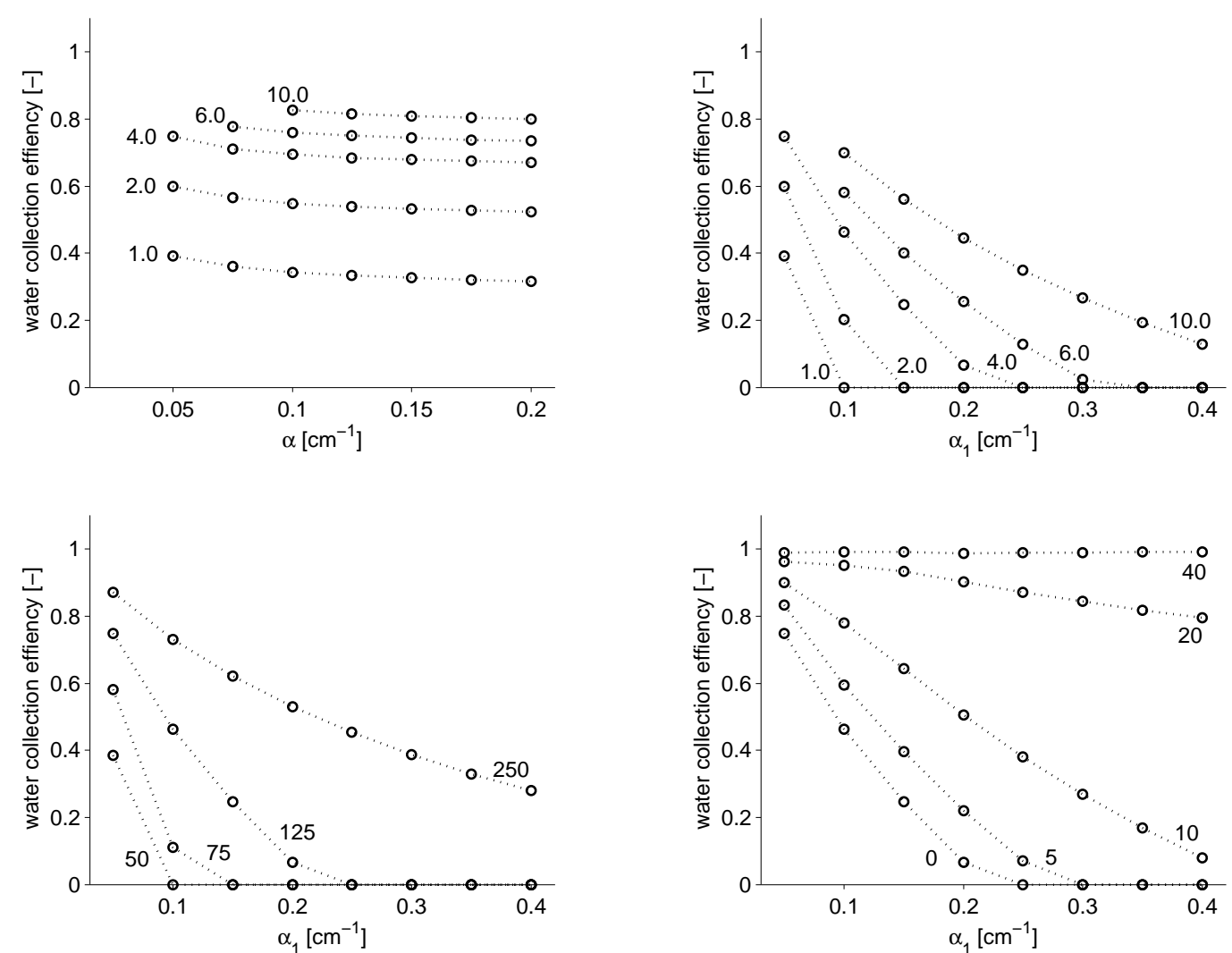

Fig. 6. Water collection efficiency as a function of pore-size index $\alpha$, infiltration intensity, lysimeter width and lysimeter geometry. Top, left: unimodal pore-size distributions. Numbers indicate infiltration intensities in $\mathrm{cm} \mathrm{d}^{-1}$; Top, right: bimodal pore-size distributions. Numbers indicate infiltration intensities in $\mathrm{cm} \mathrm{d}^{-1}$; Bottom, left: bimodal standard scenario for different lysimeter widths. Numbers indicate width in $\mathrm{cm}$; Bottom, right: bimodal standard scenario for varying height of lysimeter rim. Numbers indicate height of side wall in $\mathrm{cm}$. Further explanation in the text.

\subsubsection{Heterogeneous soils}

Figure 7 (top) displays a typical realization of the spatial distribution of the scaling factor, $\chi$, with $\sigma\left(\log _{10}(\chi)\right)=0.5$. The correlation lengths are equal in both directions $\left(\Lambda_{x}=\Lambda_{z}=10 \mathrm{~cm}\right)$. Under steady-state infiltration, heterogeneities in the distribution of the soil hydraulic properties lead to a network of vertical flow channels (Roth, 1995). This is illustrated in Fig. 7 (center and bottom), where the standard flow scenario with a lysimeter of $1.25 \mathrm{~m}$ width is modeled for the soil of Fig. 7 (top). The steady-state pressure head distribution (Fig. 7, center) is less heterogeneous than the distribution of $\chi$ and roughly resembles the pressure head distributions of the homogeneous cases (Fig. 4). It illustrates the barrier effect of the lysimeter plate, with higher pressure heads above the plate and lower heads below.

In the unimodal soil with $K_{\mathrm{s}}=100 \mathrm{~cm} \mathrm{~d}^{-1}$, the collection efficiency in the standard scenario was zero. Contrary to that, water collection for the same scenario but heterogeneous soil is $\approx 42 \%$. Figure 7 (bottom) shows the related water content distribution. In accordance with Roth (1995) the water content distribution resembles the distribution of $\chi$. Directly above the plate, the water content is higher than it would be without lysimeter. This will have an impact on the average transport velocities of solutes (see Sect. 3.1.4).

The flow field of Fig. 7 is a single random realization. In order to get representative results, the random field generation and successive simulation with the same boundary conditions was repeated 400 times for 3 different lysimeter sizes and two different values of $\sigma\left(\log _{10}(\chi)\right)$, reflecting different degrees of variability of the soil hydraulic properties. Figure 8 and Table 2 summarize the results of these Monte Carlo simulations. As shown in Sect. 3.1.2, the larger the lysimeter, the higher is the typical collection efficiency. In the case with lysimeter width $75 \mathrm{~cm}$ and $\sigma\left(\log _{10}(\chi)\right)=0.5$, approximately two thirds of all lysimeters were completely circumvented by the soil water, whereas the larger lysimeters always collected some water. Secondly, the variation of the single "measurements" decreases with increasing lysimeter size. Thirdly, the collection efficiency increases with increasing variability of the soil hydraulic properties. This is most pronounced for the smaller lysimeters, where the likeliness 
Table 2. Summary of the Monte Carlo simulations in heterogeneous 2-D-field. $\mu_{\mathrm{ce}}$ : Mean collection efficiency; $\sigma_{\mathrm{ce}}$ : standard deviation of collection efficiency; cv: coefficient of variation of collection efficiency; $\mathrm{N}_{0}$ : relative number of simulations with zero water collection.

\begin{tabular}{lrrrrr}
\hline$\sigma\left(\log _{10}(\chi)\right)$ & size & $\mu_{\text {ce }}$ & $\sigma_{\mathrm{ce}}$ & $\mathrm{cv}$ & $\mathrm{N}_{0}$ \\
- & $\mathrm{cm}$ & $\%$ & $\%$ & $\%$ & $\%$ \\
\hline \multirow{3}{*}{0.50} & 75 & 4.7 & 9.7 & 208 & 66.7 \\
& 125 & 30 & 14 & 45 & 1 \\
& 250 & 66 & 6.7 & 10.2 & 0 \\
0.75 & 75 & 21 & 22.8 & 109 & 28.2 \\
& 125 & 45 & 17 & 39 & 0 \\
& 250 & 72 & 8.5 & 11.8 & 0 \\
\hline
\end{tabular}

of distinct preferential flow channels hitting the lysimeter surface is smallest. For the very large lysimeter of $250 \mathrm{~cm}$, the increase of $\sigma\left(\log _{10}(\chi)\right)$ only slightly increased the collection efficiency.

\subsubsection{Solute transport}

Figure 9 (left) shows the breakthrough curves of the inert tracer that was applied as a short pulse on top of the soil for two simulations with steady-state water flow. One simulation was carried out with the water flow field as shown in Fig. 7. A second (reference) simulation was carried out with the identical heterogeneous distribution of soil hydraulic properties but without lysimeter as a barrier. Solute breakthrough in the undisturbed soil is quite different for different spatial positions along the lysimeter position, as indicated by the dashed lines, which represent 50 nodal points of the numerical grid in the reference simulation. It is likely that small scale measurements like suction cups would fail to give representative results for this scenario. However, the breakthrough into the lysimeter is only slightly different from the mean breakthrough through that plane in the soil without lysimeter. Thus, the lysimeter measurement may give a good estimate of the real average breakthrough in the soil. The slight retardation of the solute breakthrough into the lysimeter can be attributed to the saturated conditions above the lysimeter (Fig. 7 center and bottom). At a given water flux rate, $q$, these higher water contents lead to a smaller pore velocity, $v=q / \theta$, compared to the conditions without lysimeter.

Despite the rather representative breakthrough concentrations, the cumulative mass flux into the lysimeter is very different from the reference mass flux (Fig. 9, right). If we define a solute collection efficiency by dividing the cumulative solute mass flux through the lysimeter by the cumulative solute mass flux through the lysimeter line of the reference simulation, we get a solute collection efficiency of only $\approx 34 \%$. This means that the lysimeter measurement can not be used to determine representative solute fluxes.
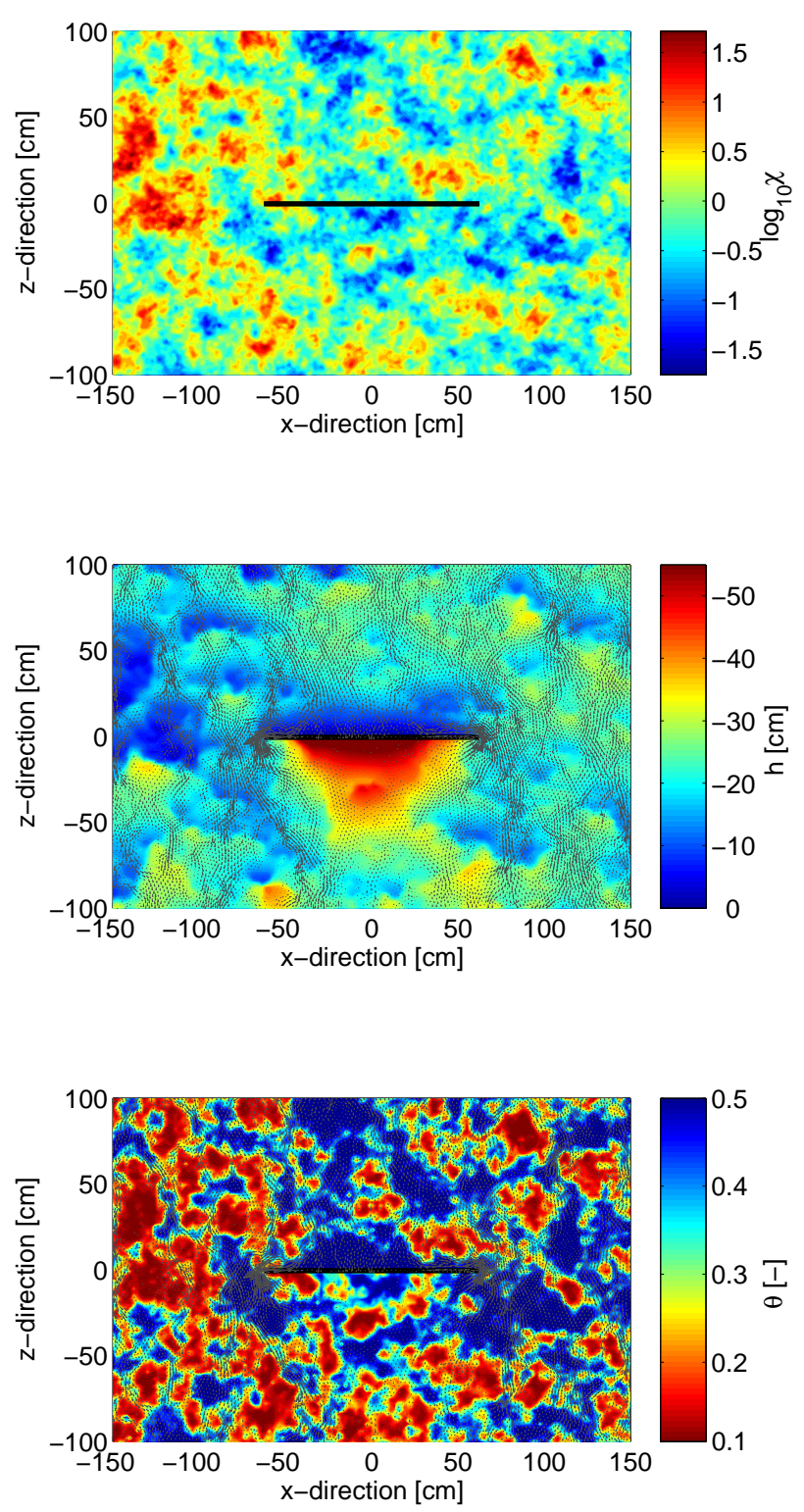

Fig. 7. Top: spatial distribution of $\log _{10}$ of scaling factor $\chi$. $\Lambda_{x}=\Lambda_{z}=10 \mathrm{~cm} ; \sigma\left(\log _{10}(\chi)\right)=0.5$. Center: corresponding steadystate pressure head distribution and flow field, unimodal standard scenario. Bottom: associated steady-state water content distribution and flow field.

\subsection{Field measurements}

The three lysimeters directly underneath the disturbed soil material collected during the tracer experiment approximately $45 \%$ (Fig. 10, top) of the applied water. The coefficient of variation between the lysimeter replicates was approximately $12 \%$. Since the evaporation loss during that short period can be neglected, this collection rate equals approximately the water collection efficiency. 

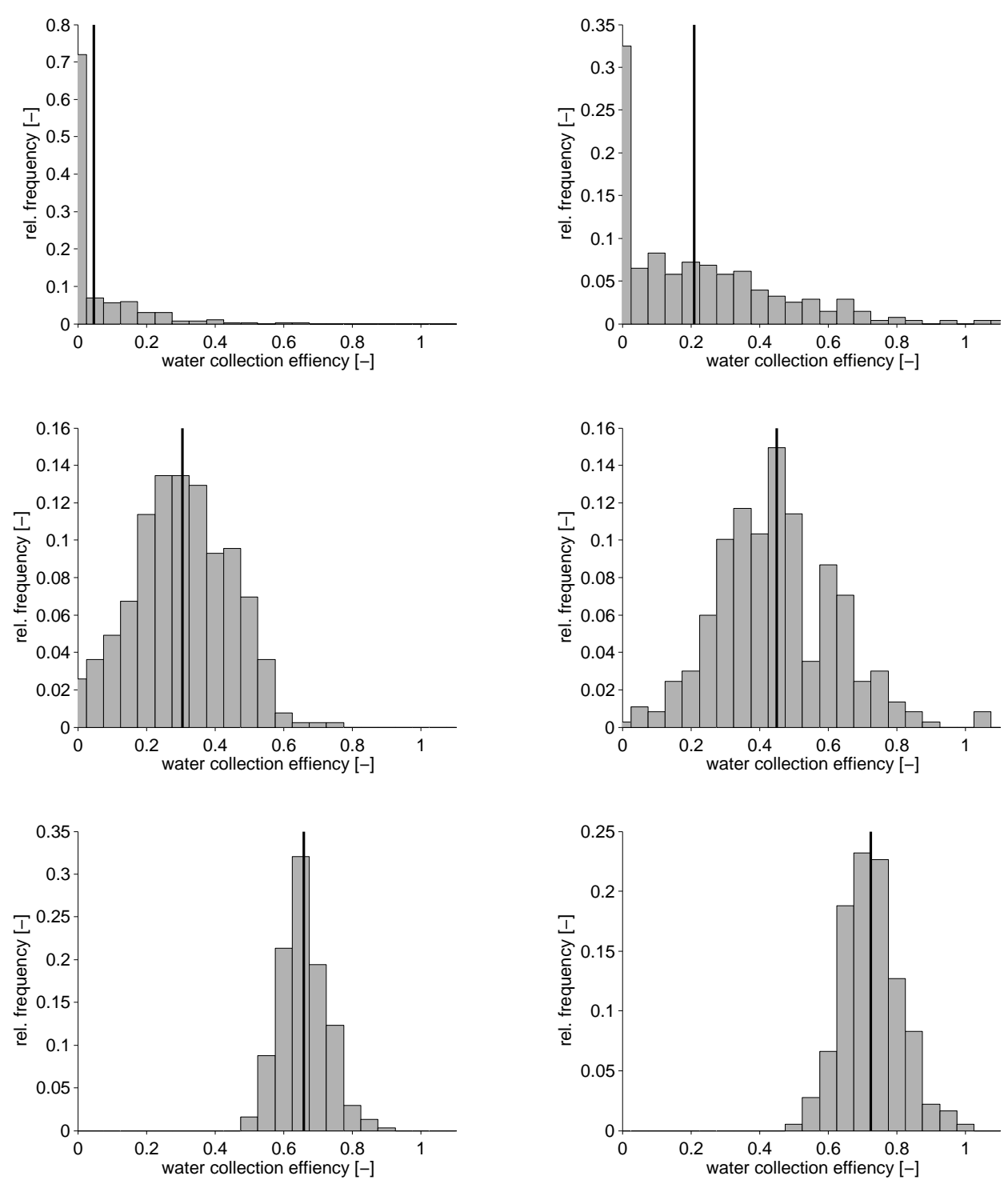

Fig. 8. Distributions of collection efficiencies from Monte Carlo simulations for different lysimeter sizes and soil heterogeneity. Upper row: lysimeter width $75 \mathrm{~cm}$; Mid row: lysimeter width $125 \mathrm{~cm}$; Lower row: lysimeter width $250 \mathrm{~cm}$. Left column: $\sigma\left(\log _{10} \chi\right)=0.5$; right column; $\sigma\left(\log _{10} \chi\right)=0.75$. Black lines show arithmetic mean of all simulations.

The relative concentrations of bromide and $\mathrm{BB}$ in the leachate of plates 1 to 3 are shown in Fig. 10 (center and bottom). Both tracers were detected already in the first sample. The concentrations of bromide were highest in the first samples with approximately $80 \%$ of the concentration of the applied tracer solution. Thereafter the concentration dropped continuously to a relative concentration of approximately 5\% after $80 \mathrm{~mm}$ of irrigation. The concentration of the reactive tracer BB was also highest in the first samples, but well below the initial concentration $\left(\approx 1 \%\right.$ of $\left.C_{0}\right)$, and dropped more irregularly and considerably later as compared to the bromide concentration.
The early arrival of both tracers and the very high bromide concentration in the first samples indicate that the collected water was almost exclusively transported by preferential flow paths. The high dilution of a reactive (BB) in contrast to an inert tracer (bromide) with comparable transport time is typical for processes that are dominated by preferential flow (Flury et al., 1994). The lysimeters that were installed in the underlying soil did not collect any water. The fact that they were circumvented completely by the water leads us to conclude that there were no distinct preferential flow paths in the underlying soil. 

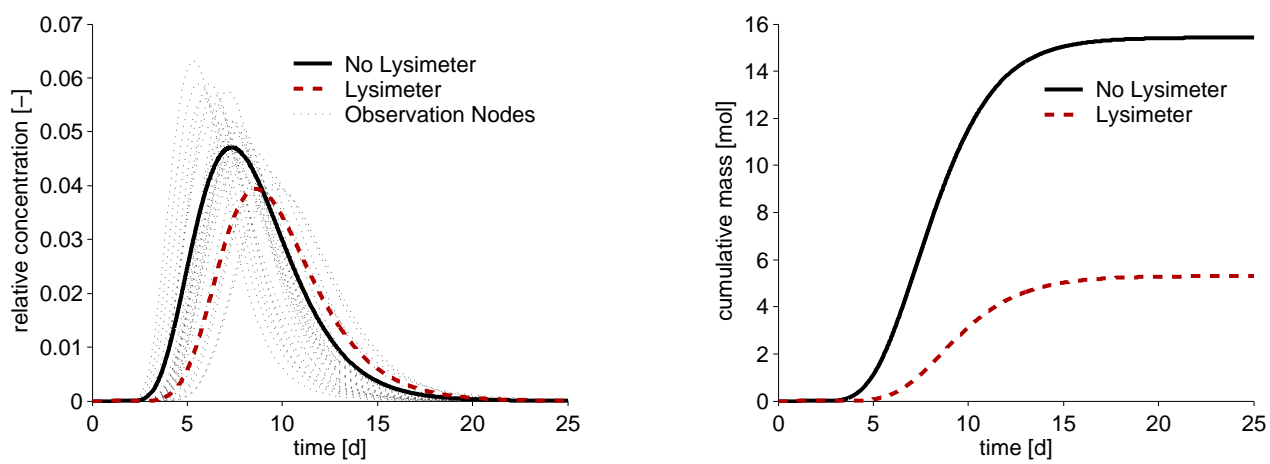

Fig. 9. Left: breakthrough curves of an inert tracer that was applied as a short pulse on top of the heterogeneous soil. Hydraulic scenario as in Fig. 7. Thin dashed lines: local solute concentrations in the undisturbed soil at different nodal points. The points are positioned at the line where lysimeter surface will be located. Black line: integrated mass flux along that line. Red dashed: flux into the lysimeter. Right: corresponding cumulative masses.

\subsection{Discussion}

Zero tension plate lysimeters collect water only when the pressure head above the plate reaches values $\geq 0 \mathrm{~cm}$. In all other cases the water completely circumvents the lysimeter. Only in soils with low hydraulic conductivities close to saturation water will be collected regularly. In coarse homogeneous or structured soils with high hydraulic conductivities, the pressure head above the lysimeter reaches zero only at very high infiltration intensities.

Heterogeneities of soil hydraulic properties can lead to water collection with the plate lysimeters even if the mean hydraulic properties for a homogeneous soil would lead to zero collection. Greater heterogeneities lead to more irregular water flow and to higher mean collection efficiencies. The size of the lysimeters also strongly influences their performance. The larger the lysimeter the higher is its collection efficiency. However, in homogeneous soils, even very large lysimeters can be largely bypassed by the soil water.

In our study for heterogeneous soils, we performed the simulations with correlation lengths $\Lambda=10 \mathrm{~cm}$ and lysimeter widths of 0.75 to $2.5 \mathrm{~m}$. The simulations showed that that in particular for the small and intermediate-sized lysimeters, single realizations gave remarkably different results, so that repetitions are necessary. This is also imperative for measurements in real soil. Increasing the lysimeter size clearly reduced the variability of the collection efficiencies, so that for larger lysimeters less repetitions are necessary. But even for the largest lysimeter width that encompasses 25 correlation lengths, individual realizations show significant variation. In the true three-dimensional case, the variation is related rather to the lysimeter's area than to its width, and the size effect might even be stronger.

The measured breakthrough of an inert solute into a plate lysimeter is only slightly retarded compared to the mean breakthrough in the soil without lysimeter, and the concentra- tions of the breakthrough curves are comparable. Since local breakthroughs at individual spatial points are quite different from each other, the lysimeter measurement may be a good estimate of the average transport in the undisturbed soil, provided the substance of interest is non-reactive, or its chemical reactivity is insensitive to hydrochemical conditions that are water saturation dependent, such as the redox potential.

Although the plates in our field study were greater than in most previous studies, the collection efficiency was much lower than those reported in the literature. We note that the smaller lysimeters that were mentioned in literature had all some sort of side walls (Radulovich and Sollins, 1987; Jemison and Fox, 1992; Zhu et al., 2002) that help to prevent bypassing of the lysimeters.

\section{Conclusions}

Large zero-tension plate lysimeters can be useful devices to collect water from preferential flow paths, as shown by simulation studies and a tracer experiment. With the new modular plate system, large water collection surfaces can be realized, while leaving the soil above the lysimeter completely undisturbed. This study shows that the collection efficiency of zero-tension plate lysimeters is highly dependent on the hydraulic properties. Especially the shape of the hydraulic functions close to saturation influences the collection efficiency. In soils with high conductivities near saturation, such as coarse soils or soils with a well-developed structural pore system, even large zero-tension plate lysimeters may be largely circumvented. In order to collect water from such soils, lysimeters with suction devices have to be used.

Heterogeneities in the soil hydraulic properties result into network of flow channels, from which representative soil water samples can best be taken by means of large lysimeter sizes. This study showed that greater heterogeneities lead to stronger preferential flow, and thus to higher mean collection 

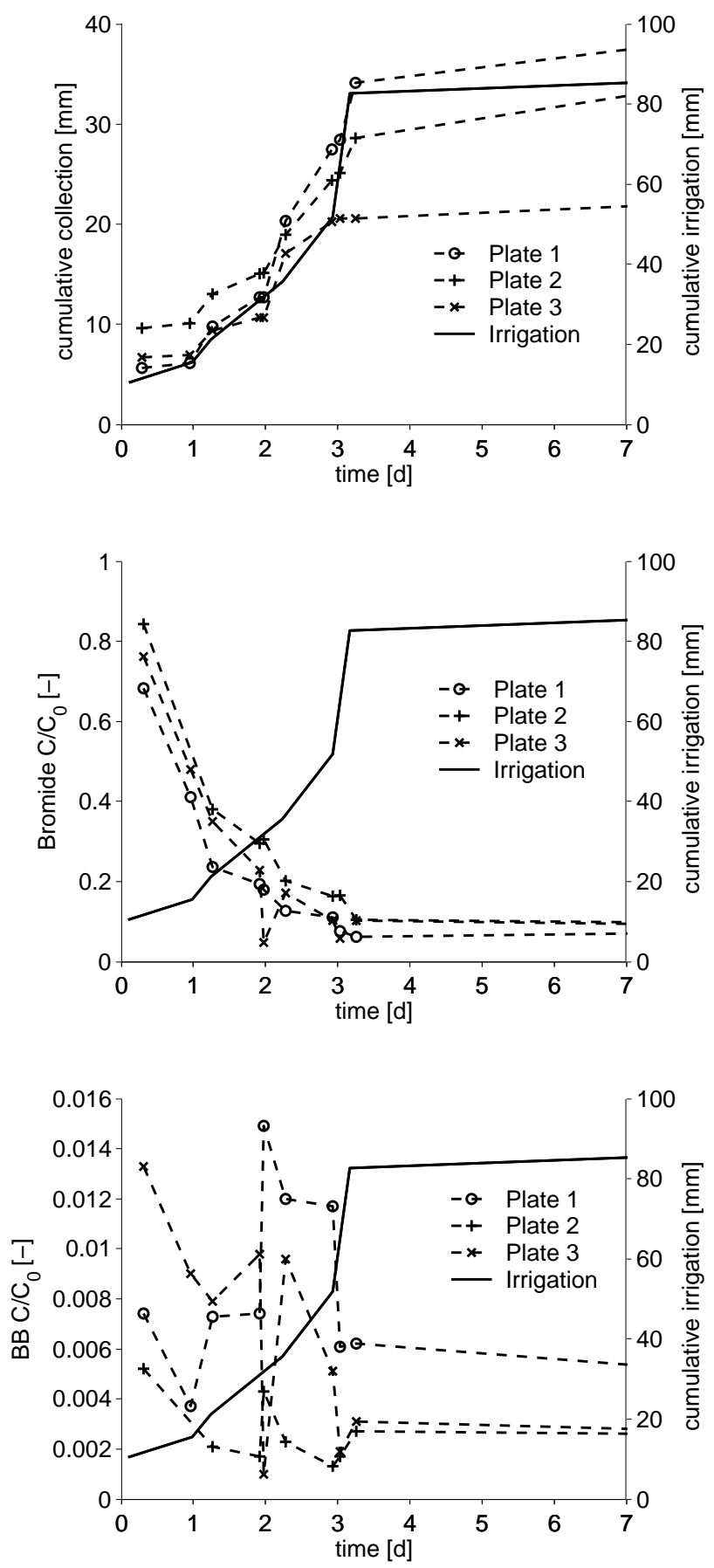

Fig. 10. Top: cumulative collection of soil water under the filling material during irrigation experiment for the three lysimeter plates; center: bromide concentration; bottom: $\mathrm{BB}$ concentration in the collected water. efficiencies. The larger the lysimeter, the larger is the mean collection efficiency and the smaller is the variability. Thus, larger lysimeters need less repetitions.

Solute breakthroughs into lysimeters are slightly delayed due to their influence on the natural flow field. However, due to its averaging over a large area, large in situ lysimeters may give more representative information about the solute flux on the plot scale as compared to point measurements with suction devices.

In a lot of soils both matrix and preferential flow play a role for water and solute transport. To sample both, large suction plates would be optimal, but such systems are not available to date. To improve the collection efficiency of zerotension plate lysimeters, the addition of small divergence barriers at the lysimeter edges is useful. At the two side edges and the front edge, this can be realized with the presented modular system without technical problems. In order to achieve representative measurements for matrix and macropore flow in soils with highly variable preferential flow channels, we believe that a combination of the modular lysimeter plate system and suction devices is optimal.

Acknowledgements. We thank the German Federal Ministry of Education and Research for financial support of the research project "Sickerwasserprognose", project number 02WP0299, and Volker Limbeck for helpful discussions about the lysimeter construction.

Edited by: F. Laio

\section{References}

Bergstrom, L.: Nitrate leaching and drainage from annual and perennial crop in tile drained plots and lysimeters, J. Environ. Qual., 16, 11-18, 1987.

Boll, J., Steenhuis, T. S., and Selker, J. S.: Fiberglass wicks for sampling of water and solutes in the vadose zone, Soil Sci. Soc. Am. J., 56, 701-707, 1992.

Boll, J., Selker, J. S., Shalit, G., and Steenhuis, T. S.: Frequency distribution of water and solute transport properties derived from pan sampler data, Water Resour. Res., 33, 2655-2664, 1997.

Briggs, L. J. and McCall, A. G.: An artificial root for inducing capillary movement of soil moisture, Science, 20, 566-569, 1904.

Cameron, D. R., Kowalenko, C. G., and Campbell, C. A.: Factors affecting nitrate and chloride leaching variability in a field plot, Soil Sci. Soc. Am. J., 43, 455-460, 1979.

Durner, W.: Hydraulic conductivity estimation for soils with heterogeneous pore structure, Water Resour. Res., 30, 211-223, 1994.

Flury, M., Flühler, H., Jury, W. A., and Leuenberger, J.: Susceptibility of soils to preferential flow of water: A field study, Water Resour. Res., 30, 1945-1954, 1994.

Gee, G. W., Ward, A. L., Caldwell, T. G., and Ritter, J. C.: A vadose zone water fluxmeter with divergence control, Water Resour. Res., 38, 1141, doi:10.1029/2001WR000816, 2002.

Gee, G. W., Newman, B. D., Green, S. R., Meissner, R., Rupp, H., Zhang, Z. F., Keller, J. M., Waugh, W. J., van der Velde, M., and Salazar, J.: Passive wick fluxmeters: Design considerations and 
field applications, Water Resour. Res., 45, W04420, doi:10.1029/ 2008WR007088, 2009.

Hagedorn, F., Mohn, J., Schleppi, P., and Flühler, H.: The role of rapid flow paths for nitrogen transformation in a forest soil: A field study with micro suction cups, Soil Sci. Soc. Am. J., 63, 1915-1923, 1999.

Jabro, J. D., Kim, Y., Evans, R. G., Iversen, W. M., and Stevens, W. B.: Passive capillary sampler for measuring soil water drainage and flux in the vadose zone: Design, performance, and enhancement, Appl. Eng. Agric., 24, 439-446, 2008.

Jemison, J. M. J. and Fox, R. H.: Estimation of zero-tension pan lysimeter collection efficiency, Soil Sci., 158, 85-94, 1992.

Kosugi, K. and Katsuyama, M.: Controlled-suction period lysimeter for measuring vertical water flux and convective chemical fluxes, Soil Sci. Soc. Am. J., 68, 371-382, 2004.

Meissner, R., Rupp, H., and Seyfarth, M.: Advances in out door lysimeter techniques, Water Air Soil Pollut., 8, 217-225, doi: 10.1007/s11267-007-9166-2, 2008.

Miller, E. E. and Miller, R. D.: Physical theory of capillary flow phenomena, J. Appl. Phys., 27, 324-332, 1956.

Mualem, Y.: A new model for predicting the hydraulic conductivity of unsaturated porous media, Water Resour. Res., 12, 513-521, 1976.

Priesack, E. and Durner, W.: Closed fom expression for the multimodal unsaturated conductivity function, Vadose Zone J., 5, 121-124, 2006.

Radulovich, R. and Sollins, P.: Improved performance of zerotension lysimeters, Soil Sci. Soc. Am. J., 51, 1386-1388, 1987.

Richard, T. L. and Steenhuis, T. S.: Tile drain sampling of preferential flow on a field scale, J. Contam. Hydrol., 3, 307-325, 1988.
Robison, W. L., Stone, E. L., and Hamilton, T. F.: Large plate lysimeter leachate collection efficiency for water being transported from soil to groundwater, Soil Sci., 169, 758-764, doi: 10.1097/01.ss.0000148736.81207.1a, 2004.

Roth, K.: Steady state flow in an unsaturated, two-dimensional, macroscopically homogeneous, Millar similar medium, Water Resour. Res, 31, 2127-2140, 1995.

Russell, A. E. and Ewel, J. J.: Leaching from a tropical Andept during big storms: a comparison of three methods, Soil Sci., 139, 181-189, 1985.

Simunek, L., Huang, K., Sejna, M., and van Genuchten, M. T.: The HYDRUS-2D Software Package for Simulating the OneDimensional Movement of Water, Heat and Multiple Solutes in Variably-Saturated Media, Version 1.0, 1999.

Sposito, G. and Jury, W. A.: Miller similtude and generalized scaling analysis, in: Scaling in Soil Physics: Prinziples and Applications, edited by: Hillel, D. and Elrick, D., SSSA Spec. Publ., vol. 25, 13-22, 1990.

van Genuchten, M. T.: A closed-form equation for predicting the hydraulic conductivity of unsaturated soils, Soil Sci. Soc. Am. J., 44, 892-898, 1980.

Weihermüller, L., Siemens, J., Deurer, M., Knoblauch, S., Rupp, H., Göttlein, A., and Pütz, T.: In Situ Soil Water Extraction: A Review, J. Environ. Qual., 36, 1735-1748, 2007.

Zhu, Y., Fox, R. H., and Toth, J. D.: Leachate Collection Efficiency of Zero-tension Pan and Passive Capillary Fiberglas Wick Lysimeters, Soil Sci. Soc. Am. J., 66, 37-43, 2002. 